\title{
Morphometric measurement of the proximal tibia to design the tibial component of total knee arthroplasty for the Thai population
}

\author{
Chotchuang Phombut ${ }^{1}$, Supakit Rooppakhun ${ }^{1 *}$ (1) and Bura Sindhupakorn ${ }^{2}$
}

\begin{abstract}
Purpose: This study evaluates the morphology of the Thai proximal tibia based on three-dimensional (3D) models to design the tibial component.

Methods: The 3D models of 480 tibias were created using reverse engineering techniques from computed tomography imaging data obtained from 240 volunteers (120 males, 120 females; range 20-50 years). Based on 3D measurements, a digital ruler was used to measure the distance between the triangular points of the models. The morphometric parameters consisted of mediolateral length (ML), anteroposterior width (AP), medial anteroposterior width (MAP), lateral anteroposterior width (LAP), central to a medial length (CM), central to a lateral length (CL), medial anterior radius (MAR), lateral anterior radius (LAR), and tibial aspect ratio (AR). An independent t-test was performed for gender differences, and K-means clustering was used to find the optimum sizes of the tibial component with a correlation between ML length and AP width in Thai people.
\end{abstract}

Results: The average morphometric parameters of Thai proximal tibia, namely $M L, A P, M A P, L A P, C M$, and $C L$, were as follows: $72.52 \pm 5.94 \mathrm{~mm}, 46.36 \pm 3.84 \mathrm{~mm}, 49.22 \pm 3.62 \mathrm{~mm}, 43.59 \pm 4.05 \mathrm{~mm}, 14.29 \pm 2.72 \mathrm{~mm}$, and $15.28 \pm 2.99 \mathrm{~mm}$, respectively. The average of MAR, LAR, and AR was $24.43 \pm 2.11 \mathrm{~mm}, 21.52 \pm 2.00 \mathrm{~mm}$, and $1.57 \pm 0.08$, respectively. All morphometric parameters in males were significantly higher than those of females. There was a difference between the Thai proximal tibia and other nationalities and a mismatch between the size of the commercial tibial component and the Thai knee. Using K-means clustering analysis, the recommended number of ML and AP is seven sizes for the practical design of tibial components to cover the Thai anatomy.

Conclusion: The design of the tibial component should be recommended to cover the anatomy of the Thai population. These data provide essential information for the specific design of Thai knee prostheses.

Keywords: Proximal tibia, Morphometric, Thais, Tibial component, Reverse engineering

\section{Introduction}

Total knee arthroplasty (TKA) is the preferred surgical procedure for severe knee osteoarthritis treatment, relieving pain and restoring function [18, 29]. A successful outcome in TKA is dependent on precise bone cutting, appropriate soft tissue balancing, and maximum

\footnotetext{
${ }^{*}$ Correspondence: supakit@sut.ac.th

1 School of Mechanical Engineering, Suranaree University of Technology, Nakhon Ratchasima 30000, Thailand

Full list of author information is available at the end of the article
}

tibial bone coverage with suitable implant size $[6,18]$. The correct size of the implant would reduce the stress applied between bone and implant interface $[2,17,18]$. Preferable compatibility between the implant and the resected surface of the bone is an essential factor for long-term survivorship in TKA [6]. In TKA, a tibial component is more highly susceptible to complications than a femoral component [4]. If a tibial component does not fit the resected surface of the proximal tibia, an orthopedic surgeon may be required to select either an oversized 
or undersized member. After TKA, a significant tibial overhanging may cause soft tissue irritation and knee pain, particularly on the medial side $[3,26]$. Conversely, an underhanging tibial component has the potential to increase tibial bone resorption, which is one of the causes of aseptic loosening [12]. Furthermore, tibial component subsidence causes misalignment and increases wear instability [35, 38]. Therefore, morphometric measurements of the proximal tibia are essential for designing and manufacturing tibial components.

Generally, two methods were used for the morphometric study of knee joints: direct and indirect. Using rulers and Vernier calipers, the direct method measured dry bone, cadaveric, and intraoperative determination. The indirect method, which included a computed tomography scan (CT) image, magnetic resonance imaging (MRI), and three-dimensional (3D) models, was also used. The advantage is that the investigation was performed digitally, which was non-destructive to the specimen. Currently, 3D models are widely used for morphometric studies of the knee joint [13, 24, 25, 32, 40]. The 3D models have been created using a reverse engineering technique, which involves digitizing and reconstructing the actual object using virtual models. The digitization phase consists of data collected from physical objects such as a sample part or prototype using various scanners. Scanning data are obtained in 3D coordinates or images representing the object's surface. The data are transferred to Computer-Aided Reverse Engineering (CARE) software during the reconstruction phase, which reconstructs the three-dimensional model with the surface represented as a polygonal mesh [13, 25, 32, 34, 40]. Based on 3D models, the digital ruler is used for measurement and assessment, which is sufficiently precise and efficient. Furthermore, the models can be customized to cut, translate, and rotate [11].

The conventional parameters consisting of mediolateral length, anteroposterior width, and the tibia aspect ratio were reported $[8,14,37,39]$. In a previous study, the anthropometric measurement of knee joints in the Thai population using MRI was reported [5]. However, morphometric parameters of the Thai proximal tibia may be inadequate for implementation in improving knee implant design. The dimension of the proximal tibia is an essential consideration in the tibial component design of total knee arthroplasty. Maximizing the surface area of coverage between the resected surface of the bone and the implant component is one approach to extending the life of knee prosthesis [17]. Therefore, this study aims to evaluate fundamental morphometric parameters of the Thai proximal tibia based on a 3D model to be a cost-effective, quick, and non-invasive method. The morphometric data of the proximal tibia are compared to the tibial component available in commercial use. The mediolateral length and anteroposterior width data are typically used to classify the numbers of tibial component sizing. The proper size of the tibial component is performed by $\mathrm{K}$-means clustering analysis and the elbow technique [27]. This study hypothesized that the morphometric data from the left and right tibias are not different. In addition, there are no different morphometric parameters between males and females, and the Thai proximal tibia has no differences from other nationalities.

\section{Material and methods \\ Data acquisition and 3D reconstruction}

Suranaree University of Technology's ethics committee for human subjects research had approved this study (EC59-60). Participants were selected from Thai volunteers ranging in age from 20 to 50 years. 480 Thai tibiae were collected from 240 volunteers (120 males and 120 females). Everyone participating in the study was informed and signed a consent form. Each participant was chosen based on the following criteria: no clinical history of knee arthritis, normal lower limb appearance, and regular alignment. Exclusion criteria included being underage, being suspected of being pregnant due to a loss of menstruation for more than 1 month, as well as refusing to undergo CT. The participants were placed in a supine position with their feet in a neutral position using a 64-slice spiral computed tomography scanner (Optima CT660, GE Healthcare, Chicago, IL, USA). The CT protocol was performed as follows: $120 \mathrm{kVA}$ with an automatic value in the range of 50 to $320 \mathrm{~mA}$, a dose reduction of $20 \%$, and a slice thickness of $2.5 \mathrm{~mm}$ with a reconstruction of $0.625 \mathrm{~mm}$ in a scan length of 30 to $90 \mathrm{~cm}$. The CT images were then imported into MIMICS Research 20.0 software (Materialise N.V., Leuven, Belgium) for segmentation. The bone-specific present from the Hounsfield unit range was employed for automatic bone segmentation (226 - $3071 \mathrm{HU})$. After the segmentation process was complete, an integrated function calculated the 3D model from the CT images was exported in stereolithography (STL) format (Fig. 1).

\section{Tibial resection model and measurements}

Before measurement, the STL files of proximal models were exported to Materialise 3-Matic Research 12.0 (Materialise N.V., Leuven, Belgium) for adjustment. As shown in Fig. 2, the proximal tibia was measured at the level of tibial resection, $6 \mathrm{~mm}$ below the lateral tibial plateau and perpendicular to the tibial mechanical axis with a 7-degree posterior slope [8]. The tibial mechanical axis was created by connecting the center of the proximal tibia and the ankle [28]. 


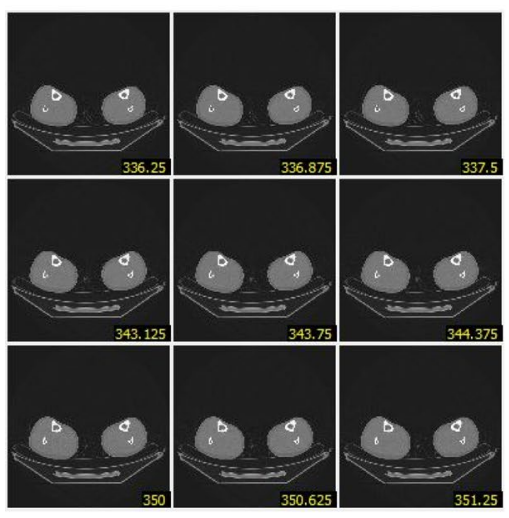

(a)

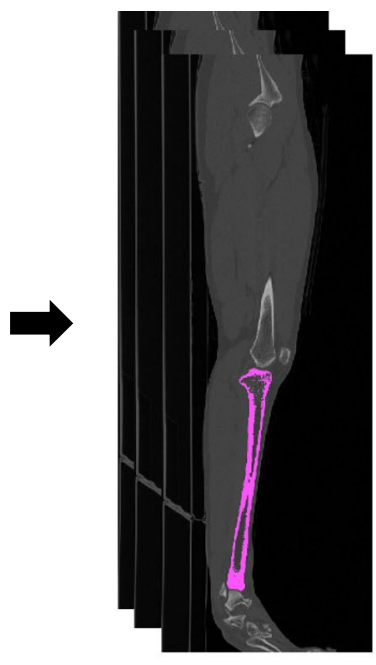

(b)
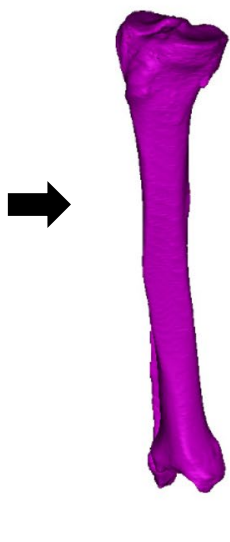

(c)

Fig. 1 3D model reconstruction of the tibia bone. a a series of raw CT images, $\mathbf{b}$ Segmentation, and $\mathbf{c}$ 3D tibia model

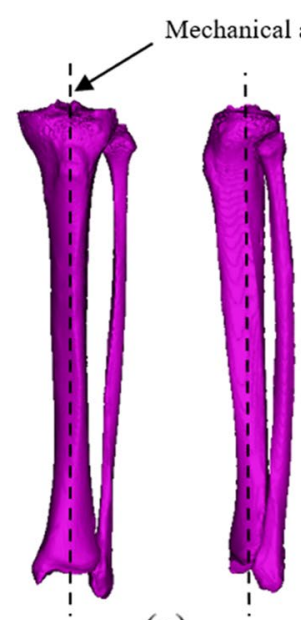

(a)

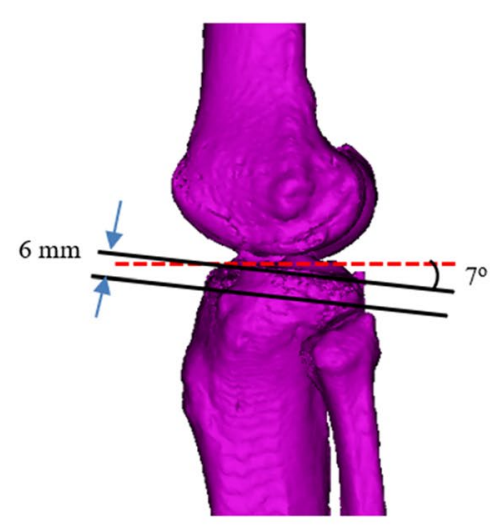

(b)

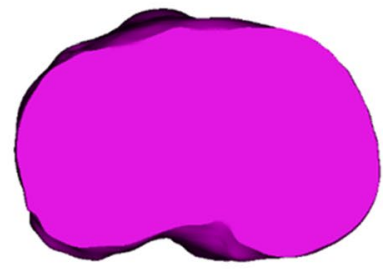

(c)

Fig. 2 3D model of the tibia bone. a Tibial mechanical axis, b Position of the resected plane of the tibia, and $\mathbf{c}$ Resected surface of the tibia

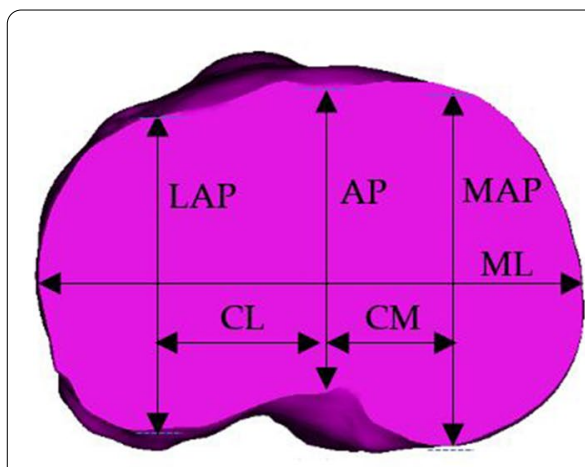

(a)

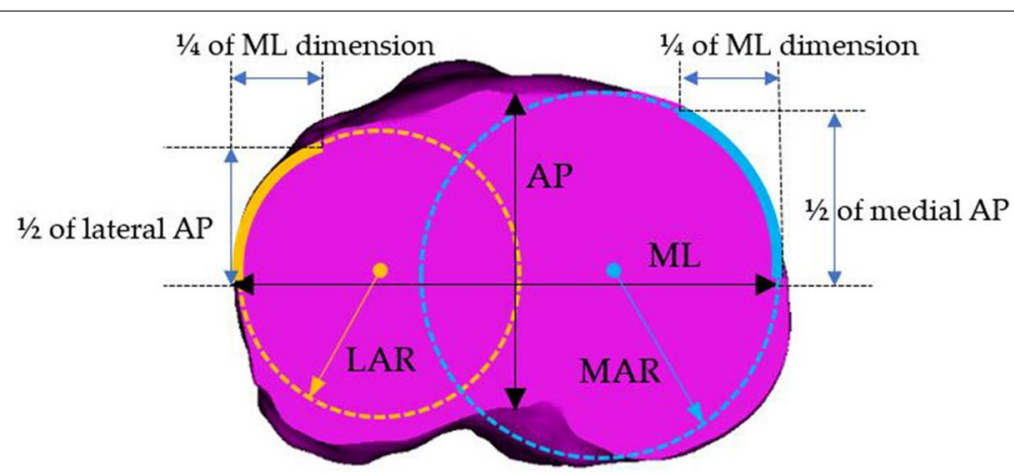

(b)

Fig. 3 The morphometric parameters of the proximal tibia. a linear measurement and $\mathbf{b}$ curvature measurement 
Figure 3 shows the morphometric measurement consisting of anteroposterior width, mediolateral length, medial and lateral anteroposterior width, central to medial length, central to lateral length, medial and lateral anterior radius, and tibial aspect ratio. The medial curvature was defined as the resection contour from the medial one-fourth of the mediolateral length for curvature measurement. The anterior curve of the medial side was defined as the anterior one-half of medial anteroposterior width. The radius of the least square best-fit circle to the anterior medial curve was then determined as the radius of the medial anterior radius. The lateral anterior radius was defined in the same way [9]. Before any measuring and instrument or assessment tool for research or clinic applications are used, reliability must be established. The intra-class correlation coefficient (ICC) is a commonly used statistic to evaluate reliability, such as intra- and inter-observer agreements [16]. Two observers measured morphometric parameters on 20 random tibias in three replicates, and one observer measured the same tibia twice with a two-week interval. The morphometric parameters of the proximal tibia, as shown in Table 1, were abbreviated and defined as follows: three lengths, three widths, two radii, and one ratio.

\section{Statistical analysis}

The data were presented, including the mean and standard deviation (SD). A paired t-test was then used to evaluate the differences in the variables between the sides. An independent $t$-test was performed to compare mean differences between genders. Pearson's correlation coefficient ( $r$ ) was calculated to determine the relationships between the morphometric parameters. A statistically significant difference was defined by a $p$-value less than 0.05. Furthermore, the K-means clustering analysis and the elbow method were used to determine proper tibial component sizes. The statistical software SPSS (SPSS Inc., Chicago, IL, USA) analyzed the measured data.

\section{Results \\ Reliability analyses}

Accordingly, intra-class correlation coefficient analysis (Table 2), all parameters were found to be highly reliable in the 0.88 to 0.99 range, according to intra-rater reliability. Likewise, the inter-rater reliability value was between 0.80 and 0.97 . The high value of ICC indicated that the measurement was highly reproducible [22].

\section{Comparison of morphometric parameters of the proximal tibia between sides}

Table 3 shows the results of the statistical comparison of the measurements of the left and right tibia. There were no statistically significant differences between these measurements. This finding was similar to the previous research, namely the morphometric study of the femur and ankle $[6,19]$. Thus, the morphometric or anthropometric studies of a femur, tibia, and ankle could be performed either left or right.

Table 2 The value of the intra-class correlation coefficient for various morphometric parameters

\begin{tabular}{lll}
\hline Parameters & Intra-rater & Inter-rater \\
\hline ML & 0.98 & 0.97 \\
AP & 0.95 & 0.94 \\
MAP & 0.95 & 0.89 \\
LAP & 0.98 & 0.81 \\
CM & 0.88 & 0.94 \\
CL & 0.89 & 0.85 \\
MAR & 0.99 & 0.80 \\
LAR & 0.98 & 0.80
\end{tabular}

Table 1 Abbreviation and definition of proximal tibial morphometric parameters

\begin{tabular}{|c|c|c|}
\hline Abbreviation & Measurement & Definition \\
\hline$M L$ & Mediolateral length & $\begin{array}{l}\text { The longest mediolateral line of the proximal cut tibial surface, parallel and collinear to the surgical } \\
\text { epicondylar axis of the femur }\end{array}$ \\
\hline AP & Anteroposterior width & The distance of a perpendicular line is drawn through the midpoint of the $\mathrm{ML}$ \\
\hline MAP & Medial anteroposterior width & $\begin{array}{l}\text { The distance of a parallel line to the AP line and passed through the extreme posterior point to the } \\
\text { extreme anterior point of the medial tibial condyle }\end{array}$ \\
\hline LAP & Lateral anteroposterior width & $\begin{array}{l}\text { The distance of a parallel line to the AP line and passed through the extreme posterior point to the } \\
\text { extreme anterior point of the lateral tibial condyle }\end{array}$ \\
\hline CM & Central to a medial length & The distances of the MAP lines to the AP line. \\
\hline $\mathrm{CL}$ & Central to a lateral length & The distances of the LAP lines to the AP line. \\
\hline MAR & Medial anterior radius & The least-squares best-fit circle creates the radius-to-anterior medial profile \\
\hline LAR & Lateral anterior radius & The least-squares best-fit circle creates the radius-to-anterior lateral profile \\
\hline$A R$ & Aspect ratio & Tibial aspect ratio: ML length divided by AP width \\
\hline
\end{tabular}


Table 3 Symmetry analysis of the proximal tibia parameters in mean \pm SD $(\mathrm{mm})$

\begin{tabular}{llll}
\hline Parameters & $\begin{array}{l}\text { Right } \\
(\boldsymbol{n}=\mathbf{2 4 0})\end{array}$ & $\begin{array}{l}\text { Left } \\
(\boldsymbol{n}=\mathbf{2 4 0})\end{array}$ & $\boldsymbol{p}$-value \\
\hline ML & $72.49 \pm 5.90$ & $72.55 \pm 5.99$ & 0.444 \\
AP & $46.29 \pm 3.81$ & $46.42 \pm 3.87$ & 0.062 \\
MAP & $49.21 \pm 3.64$ & $49.22 \pm 3.60$ & 0.886 \\
LAP & $43.58 \pm 4.04$ & $43.60 \pm 4.06$ & 0.664 \\
CM & $14.27 \pm 2.70$ & $14.30 \pm 2.74$ & 0.662 \\
CL & $15.30 \pm 2.97$ & $15.24 \pm 3.00$ & 0.421 \\
MAR & $24.40 \pm 2.13$ & $24.45 \pm 2.10$ & 0.058 \\
LAR & $21.48 \pm 2.01$ & $21.54 \pm 1.99$ & 0.077 \\
AR & $1.57 \pm 0.07$ & $1.56 \pm 0.08$ & 0.308 \\
\hline
\end{tabular}

\section{Summary of morphometric measurement of the proximal tibia}

Table 4 summarizes the morphometric parameters of the proximal tibia in terms of mean $\pm S D(\mathrm{~mm})$. The results exhibited a significant difference between the genders based on the available data. The male group had higher morphometric parameters than the female group $(p<0.05)$. However, the $p$-value of AR was 0.012 , indicating a statistically significant difference. However, the aspect ratio of Thai tibial may range from 1.55 to 1.57 .

\section{Correlation and linear regression analyses}

The first ten of the linear regression and high correlation coefficients of the morphology of Thai proximal tibia are shown in Table 5 . The relationship between ML and LAP had the highest correlation coefficient value: 0.86 . However, another parameter relation had strong coefficients of correlation of more than 0.7 observed. For the rest of the parameter pairs, the r-value falls within a range between 0.17 and 0.74 . Furthermore, high and robust parameter correlation pairs were shown as linear

Table 4 Summary of Thai proximal tibia morphology measurements in mean SD (mm)

\begin{tabular}{lllll}
\hline Parameters & $\begin{array}{l}\text { Total } \\
(\boldsymbol{n}=\mathbf{4 8 0})\end{array}$ & $\begin{array}{l}\text { Male } \\
(\boldsymbol{n}=\mathbf{2 4 0})\end{array}$ & $\begin{array}{l}\text { Female } \\
(\boldsymbol{n}=\mathbf{2 4 0})\end{array}$ & $\boldsymbol{p}$-value \\
\hline ML & $72.52 \pm 5.94$ & $77.52 \pm 3.22$ & $67.51 \pm 3.17$ & $<0.0001$ \\
AP & $46.36 \pm 3.84$ & $49.26 \pm 2.49$ & $43.45 \pm 2.53$ & $<0.0001$ \\
MAP & $49.22 \pm 3.62$ & $51.79 \pm 2.64$ & $46.65 \pm 2.44$ & $<0.0001$ \\
LAP & $43.59 \pm 4.05$ & $46.73 \pm 2.73$ & $40.45 \pm 2.37$ & $<0.0001$ \\
CM & $14.29 \pm 2.72$ & $15.71 \pm 2.65$ & $12.87 \pm 1.92$ & $<0.0001$ \\
CL & $15.28 \pm 2.99$ & $16.35 \pm 3.11$ & $14.20 \pm 2.43$ & $<0.0001$ \\
MAR & $24.43 \pm 2.11$ & $26.00 \pm 1.41$ & $22.86 \pm 1.43$ & $<0.0001$ \\
LAR & $21.52 \pm 2.00$ & $23.00 \pm 1.38$ & $20.03 \pm 1.29$ & $<0.0001$ \\
AR & $1.57 \pm 0.08$ & $1.57 \pm 0.07$ & $1.55 \pm 0.09$ & 0.012 \\
\hline
\end{tabular}

Table 5 The equations of morphometric parameters' high pairwise correlation for Thais

\begin{tabular}{lll}
\hline Parameters & Linear regression equation & $\begin{array}{l}\text { Correlation } \\
\text { coefficient } \\
(\mathbf{r})\end{array}$ \\
\hline ML vs. LAP & $L A P=1.21+0.58 \mathrm{ML}$ & 0.859 \\
LAP vs. AP & $L A P=2.65+0.88 \mathrm{AP}$ & 0.838 \\
ML vs. MAP & $M A P=13.10+0.50 \mathrm{ML}$ & 0.818 \\
MAP vs. LAP & $\mathrm{MAP}=17.51+0.73 \mathrm{LAP}$ & 0.814 \\
MAR vs. LAR & $L A R=2.74+0.77 \mathrm{MAR}$ & 0.812 \\
ML vs. AP & $\mathrm{AP}=0.83+0.52 \mathrm{ML}$ & 0.811 \\
$M A P$ vs. $A P$ & $\mathrm{AP}=4.42+0.85 \mathrm{MAP}$ & 0.802 \\
$M L$ vs. LAR & $L A R=1.92+0.27 \mathrm{ML}$ & 0.802 \\
$M A R$ vs. ML & $M A R=5.00+0.27 \mathrm{ML}$ & 0.753 \\
$M A R$ vs. MAP & $M A R=3.02+0.44 \mathrm{MAP}$ & 0.744 \\
\hline
\end{tabular}

regression equations to be helpful in predicting other parameters.

\section{Comparison of morphometric measurement with other populations}

Using a two-sample t-test, Table 6 shows the result of comparison morphometric parameters with various populations, including Indians, Koreans, Americans, Japanese, Chinese, Iranians, and Turkish. This study found that the ML of Thai differed from most ethnic groups, except for Iranians. However, the Thai ML was similar to Asians but smaller than Americans and Caucasians. There were significant differences in AP of Thai to Koreans, Japanese, Chinese, and Turkish, but slightly lower than Japanese and Chinese. The MAP of Thai was different from other populations and greater than Indians and Koreans. In addition, the LAP differed from other populations except for Turkish. The average of AR in the Thais was significantly higher than Caucasian, which was close to Koreans and Chinese but smaller than Iranians and Turkish.

Besides, the MAR and LAR of proximal tibias were determined and compared with other studies. The measurement results are shown in Table 7. Compared to the other studies in Caucasians, Indians, and Japanese, the MAR and LAR were more petite, especially on the medial side. However, the LAR was similar to Japanese for males and Indians and Caucasians for females.

\section{Comparison to the current tibial implants}

Generally, the ML and AP are used to select the implant size and identify the ideal size of the tibial component required. Therefore, these parameters were compared to the dimension of the commercial implant commonly used in Thailand. In this study, the typical commercial 
Table 6 Comparison of the morphometric parameters with other nationalities in mean \pm SD ( $\mathrm{mm}$ )

\begin{tabular}{|c|c|c|c|c|c|}
\hline \multirow[t]{2}{*}{ Studies } & \multicolumn{5}{|l|}{ Parameters } \\
\hline & ML & AP & MAP & LAP & $A R$ \\
\hline \multirow[t]{2}{*}{ This study } & $77.52 \pm 3.22(\mathrm{M})$ & $49.26 \pm 2.49(\mathrm{M})$ & $51.79 \pm 2.64(\mathrm{M})$ & $46.73 \pm 2.73(\mathrm{M})$ & $1.57 \pm 0.07(\mathrm{M})$ \\
\hline & $67.51 \pm 3.17(F)$ & $43.45 \pm 2.53(\mathrm{~F})$ & $46.65 \pm 2.44(F)$ & $40.45 \pm 2.37(\mathrm{~F})$ & $1.55 \pm 0.09(\mathrm{~F})$ \\
\hline \multicolumn{6}{|l|}{ Indians } \\
\hline \multirow{4}{*}{$\begin{array}{l}\text { Bansal et al. [1] } \\
\text { Reddy et al. [33] }\end{array}$} & $72.02 \pm 5.13(\mathrm{M})^{*}$ & $47.80 \pm 3.65(M)$ & $48.58 \pm 4.41(\mathrm{M})^{*}$ & $45.54 \pm 1.00(M)^{*}$ & \\
\hline & $67.58 \pm 5.69(\mathrm{~F})$ & $43.53 \pm 3.40(\mathrm{~F})$ & $43.19 \pm 4.74(F)^{*}$ & $42.97 \pm 2.92(F)^{*}$ & \\
\hline & $74.70 \pm 3.60(\mathrm{M})^{*}$ & $48.90 \pm 2.60(\mathrm{M})$ & & & \\
\hline & $65.80 \pm 3.90(\mathrm{~F})^{*}$ & $43.10 \pm 3.00(\mathrm{~F})$ & & & \\
\hline \multicolumn{6}{|l|}{ Koreans } \\
\hline \multirow[t]{2}{*}{ Kwak et al. [23] } & $76.10 \pm 4.00(\mathrm{M})^{*}$ & $48.20 \pm 3.30(\mathrm{M})^{*}$ & $48.50 \pm 3.70(\mathrm{M})^{*}$ & $44.60 \pm 3.20(M)^{*}$ & 1.58(M) \\
\hline & $67.64 \pm 3.12(F)$ & $43.20 \pm 2.30(\mathrm{~F})$ & $43.50 \pm 2.90(F)^{*}$ & $39.80 \pm 2.50(\mathrm{~F})$ & $1.56(\mathrm{~F})$ \\
\hline \multicolumn{6}{|l|}{ Americans } \\
\hline \multirow[t]{2}{*}{ Mensch et al. [30] } & $80.30 \pm 3.70(\mathrm{M})^{*}$ & & $54.30 \pm 3.60(\mathrm{M})^{*}$ & $43.50 \pm 2.80(M)^{*}$ & \\
\hline & $70.10 \pm 2.80(\mathrm{~F})^{*}$ & & $46.00 \pm 2.10(F)$ & $38.30 \pm 2.60(F)^{*}$ & \\
\hline \multicolumn{6}{|l|}{ Caucasians } \\
\hline \multirow[t]{2}{*}{ Dai et al. [9] } & $78.13 \pm 3.91(\mathrm{M})$ & & $54.35 \pm 2.99(\mathrm{M})^{*}$ & $48.62 \pm 2.95(M)^{*}$ & $1.12 \pm 0.05(\mathrm{M})^{*}$ \\
\hline & $69.11 \pm 2.82(\mathrm{~F})$ & & $47.95 \pm 2.36(F)^{*}$ & $42.63 \pm 2.31(F)^{*}$ & $1.13 \pm 0.05(F)^{*}$ \\
\hline \multicolumn{6}{|l|}{ Japanese } \\
\hline \multirow{4}{*}{$\begin{array}{l}\text { Uehara et al. [37] } \\
\text { Miyatake et al. [31] }\end{array}$} & $77.90 \pm 4.10(\mathrm{M})$ & $54.10 \pm 3.00(\mathrm{M})^{*}$ & & & \\
\hline & $69.50 \pm 3.40(\mathrm{~F})^{*}$ & $49.20 \pm 2.90(F)^{*}$ & $51.00 \pm 2.60(\mathrm{M})^{*}$ & $46.10 \pm 2.40(\mathrm{M})$ & \\
\hline & $76.40 \pm 3.20(\mathrm{M})^{*}$ & & $46.00 \pm 2.70(\mathrm{~F})^{*}$ & $41.30 \pm 2.20(F)^{*}$ & \\
\hline & $68.30 \pm 2.90(\mathrm{~F})^{*}$ & & & & \\
\hline \multicolumn{6}{|l|}{ Chinese } \\
\hline \multirow{4}{*}{$\begin{array}{l}\text { Cheng et al. [8] } \\
\text { Yue et al. [39] }\end{array}$} & $76.40 \pm 2.80(\mathrm{M})^{*}$ & $51.30 \pm 2.00(\mathrm{M})^{*}$ & $53.30 \pm 2.50(\mathrm{M})^{*}$ & $47.70 \pm 2.70(\mathrm{M})^{*}$ & $1.49 \pm 5.70(\mathrm{M})$ \\
\hline & $68.80 \pm 4.60(F)^{*}$ & $45.70 \pm 1.90(F)^{*}$ & $47.50 \pm 2.40(F)^{*}$ & $42.40 \pm 2.30(F)^{*}$ & $1.51 \pm 6.10(\mathrm{~F})$ \\
\hline & $75.20 \pm 3.60(M)^{*}$ & $41.50 \pm 2.10(\mathrm{M})^{*}$ & $46.10 \pm 2.10(\mathrm{M})^{*}$ & $36.80 \pm 2.10(M)^{*}$ & $1.82 \pm 0.07(\mathrm{M})^{*}$ \\
\hline & $66.20 \pm 2.10(F)$ & $37.30 \pm 2.80(F)^{*}$ & $41.50 \pm 3.00(F)^{*}$ & $33.20 \pm 3.20(F)^{*}$ & $1.78 \pm 0.10(\mathrm{~F})^{*}$ \\
\hline \multicolumn{6}{|l|}{ Iranians } \\
\hline \multirow[t]{2}{*}{ Karimi et al. [21] } & $77.80 \pm 3.78(\mathrm{M})$ & $48.79 \pm 3.08(\mathrm{M})$ & $53.14 \pm 3.21(\mathrm{M})^{*}$ & $51.94 \pm 3.57(\mathrm{M})^{*}$ & $1.60 \pm 0.10(\mathrm{M})^{*}$ \\
\hline & $66.52 \pm 4.48(F)$ & $43.07 \pm 2.68(\mathrm{~F})$ & $45.48 \pm 2.98(\mathrm{~F})^{*}$ & $43.71 \pm 3.46(F)^{*}$ & $1.55 \pm 0.11(F)$ \\
\hline \multicolumn{6}{|l|}{ Turkish } \\
\hline \multirow[t]{2}{*}{ Erkocak et al. [10] } & $77.10 \pm 5.10(\mathrm{M})$ & $47.60 \pm 3.80(M)^{*}$ & $53.90 \pm 4.20(\mathrm{M})^{*}$ & $45.90 \pm 3.70(\mathrm{M})$ & $1.62(M)^{*}$ \\
\hline & $68.70 \pm 3.60(\mathrm{~F})^{*}$ & $40.90 \pm 3.10(F)^{*}$ & $47.50 \pm 3.90(F)^{*}$ & $39.90 \pm 3.30(F)$ & $1.68(F)^{*}$ \\
\hline
\end{tabular}

*Statistical significance $p<0.05$

Table 7 Comparison of the anterior radius of proximal tibias with other studies in mean \pm SD $(\mathrm{mm})$

\begin{tabular}{|c|c|c|c|c|c|}
\hline \multirow[t]{2}{*}{ Studies } & \multirow[t]{2}{*}{ Population } & \multicolumn{2}{|l|}{ MAR } & \multicolumn{2}{|l|}{ LAR } \\
\hline & & Male & Female & Male & Female \\
\hline This study & Thais & $26.00 \pm 1.41$ & $22.86 \pm 1.43$ & $23.00 \pm 1.38$ & $20.03 \pm 1.29$ \\
\hline Bansal et al. [1] & Indians & $29.95 \pm 2.87^{*}$ & $26.74 \pm 3.17^{*}$ & $22.21 \pm 3.31^{*}$ & $19.99 \pm 3.57$ \\
\hline \multirow[t]{3}{*}{ Dai et al. [9] } & Caucasians & $38.67 \pm 7.61^{*}$ & $34.39 \pm 6.40^{*}$ & $24.16 \pm 4.22^{*}$ & $20.47 \pm 3.77$ \\
\hline & Indians & $39.32 \pm 9.57^{*}$ & $32.92 \pm 8.37^{*}$ & $24.22 \pm 4.07^{*}$ & $18.43 \pm 3.52^{*}$ \\
\hline & Japanese & $35.23 \pm 7.57^{*}$ & $29.59 \pm 4.80^{*}$ & $22.50 \pm 2.59$ & $18.74 \pm 2.50^{*}$ \\
\hline
\end{tabular}


systems, including the ZIMMER (Nexgen), DEPUY (Sigma), STRYKER (Scorpio), and SMITH \& NEPHEW (Genesis II), were used and displayed in a scatter diagram. Figure 4 depicts the relationship between AP and ML of the tibial implant and Thai tibia dimensions in males and females. The results revealed a mismatch between Thai tibial and commercial component dimensions, especially in the lack of coverage of the ML dimension. The AP dimension of typical implants tended not to be suitable to Thai anatomy with high mediolateral overhang. In addition, this finding showed that Thai females required smaller implant sizes with the same AP, while Thai males required a more significant ML than females. Although the size number of commercial implants covered the Thai tibia, the sizes of all implants did not match the Thai tibia. As a result, the tibial component should be improved to be suitable for the Thai population, for example, the decreasing of the AP dimension and increasing the number of the ML dimension in the same AP such as the Nexgen system.

To determine whether the tibial component of total knee arthroplasty would be appropriate for the Thai population or not, the tibial aspect ratio was calculated and compared to four different implants. Figure 5 shows the relationship between aspect ratio and AP. The results revealed that the aspect ratio had a definite negative correlation with the increasing AP. The aspect ratio of Thai males was more significant than Thai females with the same AP. Only the ZIMMER (Nexgen) system displayed a changing aspect ratio compared to the four implants. However, it was increasing, whereas the aspect ratio of the Thai tibia was decreasing with the increasing AP. Furthermore, the aspect ratio of the other implants showed a relatively constant ratio.

\section{Discussion}

In this study, the morphometric data of the Thai proximal tibia was assessed using 3D models. Reverse engineering techniques were used to reconstruct these models from CT data. Based on the 3D measurements, it provided greater convenience and accuracy than alternative methods [11]. The proximal tibia morphometric parameters are utilized for various purposes, including sex determination, ethnic identification, and primary data to design the total knee prosthesis $[1,6,8,15,37,39]$.

According to the findings of this study, the MAP has higher values than LAP, consistent with other reports $[14,23,30]$. In addition, the MAR was more significant than the LAR. The CM and CL did not have equal dimensions, with the $\mathrm{CM}$ being small. These findings could imply that an asymmetric prosthesis design could improve coverage between the implants and the resected

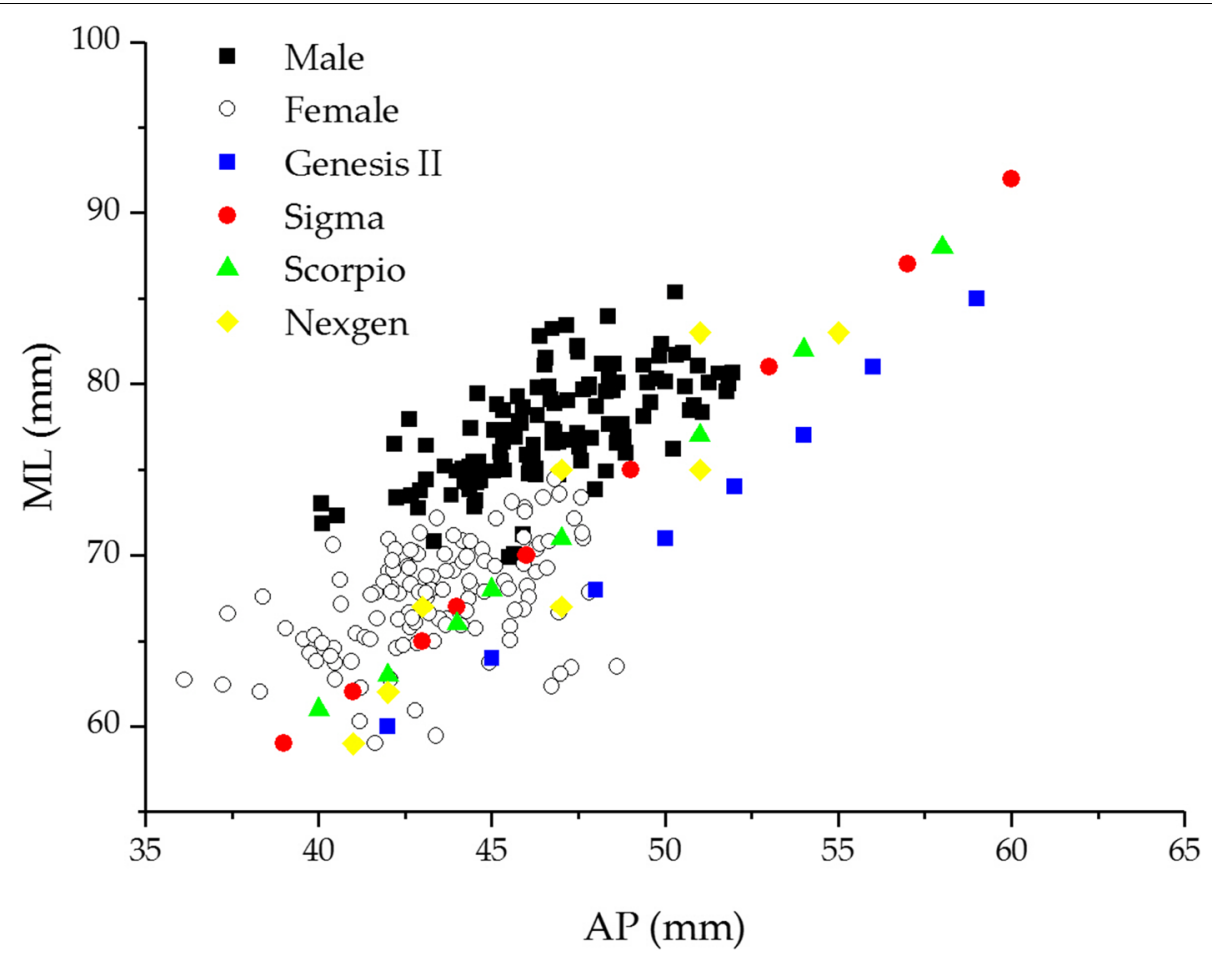

Fig. 4 The relationship of anteroposterior width (AP) and mediolateral length (ML) compare between Thai proximal tibia data and four commercial tibial components 


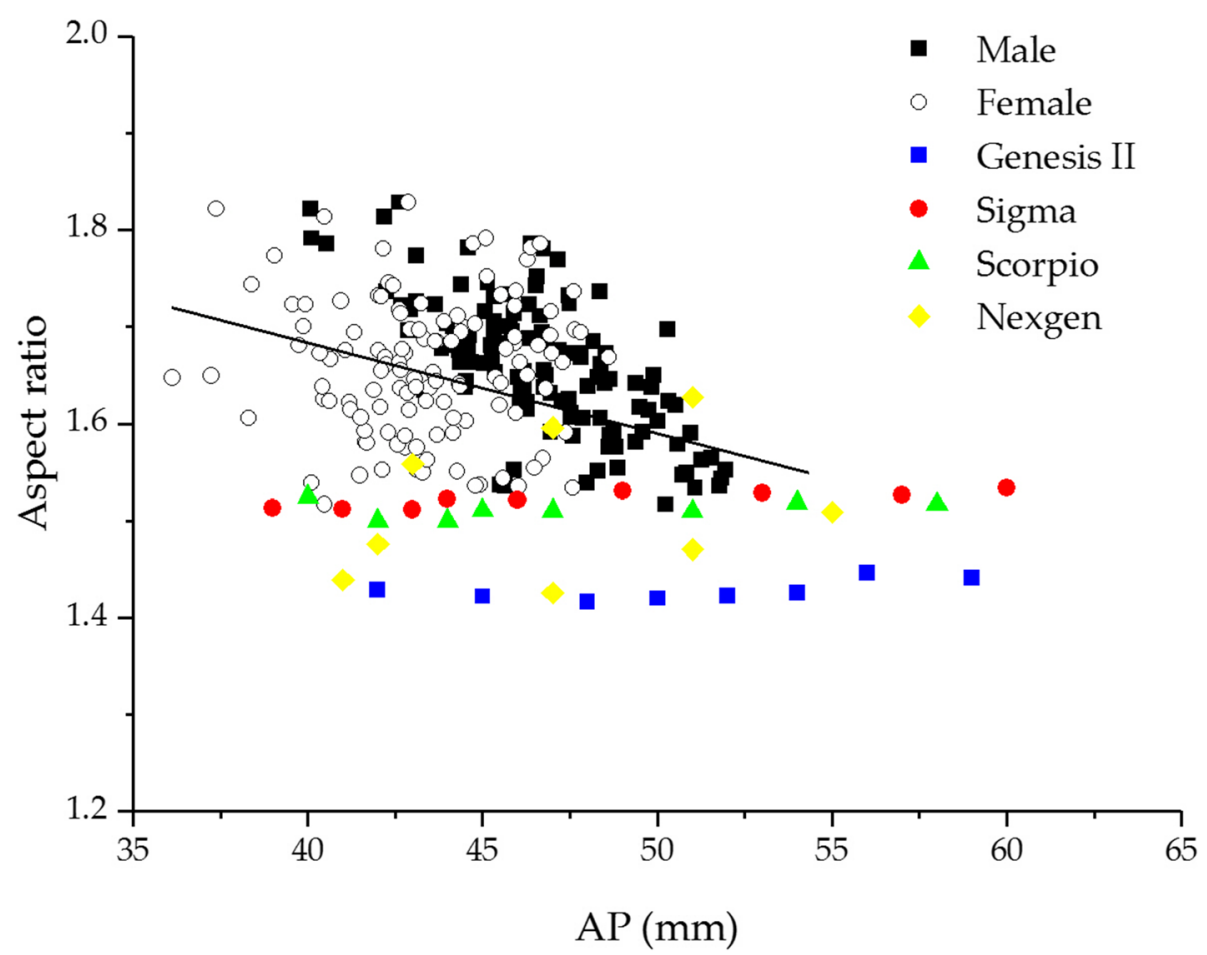

Fig. 5 Tibial aspect ratio (AR) and anteroposterior width (AP) of Thai knee compared with four tibial components

surface of the tibia. Alternatively, several authors have indicated that the bone coverage of symmetric design can be improved [17]. Further study is needed to determine whether an asymmetric design is better or not. Furthermore, the dimensions of the right and left sides were not significantly different. When comparing male and female proximal tibia parameters, all the male parameters were significantly higher than females, as discovered by previous studies [5, 8, 23, 24, 30, 37]. However, the males and females had slightly different aspect ratios. Thais were clearly determined to have a range of the tibial aspect ratio between 1.55 to 1.57 . In addition, the anterior radius was measured on both the medial and lateral plateaus of the tibia, which to our knowledge, has not ever been reported in Thai morphometric studies. The proximal tibia parameters in this study revealed that ML, AP, and AR were slightly higher than previously reported studies concerning anthropometry of the knee joint in Thais measured based on MRI images [5]. These differences may be caused by different parameter definitions and methods of measurement. For example, this study performed measurements at the level of tibial resection $6 \mathrm{~mm}$ below the lateral tibial plateau while other studies [5] measured at the level of tibial resection $10 \mathrm{~mm}$.

The morphometric data on the proximal tibia in males and females were analyzed using linear regression and correlation analysis as presented in Table 5 to assess the relationship between each parameter. Between specific parameters, there was a positive correlation. ML and LAP possessed the highest correlation coefficients (0.859). Furthermore, the correlation coefficients between ML and MAP, ML and AP were 0.818 and 0.811, respectively, a fact also reported in Korean studies [23]. The high correlation (between 0.7 to 1.0) indicates a highly linear relationship between the pairwise parameters. The linear regression equation was considered to estimate the dependent variable precisely, such as predicting other morphometric parameters.

Asian knees are smaller than Caucasian knees, according to numerous studies [8, 23, 37]. According to the present study, Koreans, Japanese, Chinese, Iranians, and Turkish had a similar ML and AP, including the medial and lateral sides. However, several parameters differed somewhat from this study, such as slightly higher AR in Chinese [39]. This difference could be due to their bone resection technique compared to this study [23]. Besides, the values of morphometric parameters were slightly higher in comparison to Indians. However, ML, MAP, and LAP were smaller than Americans, clearly evidenced in males. It can be seen that the morphometric of the proximal tibia differs between nationalities. As a result, knee prostheses designed using Western anatomy may not suit other 


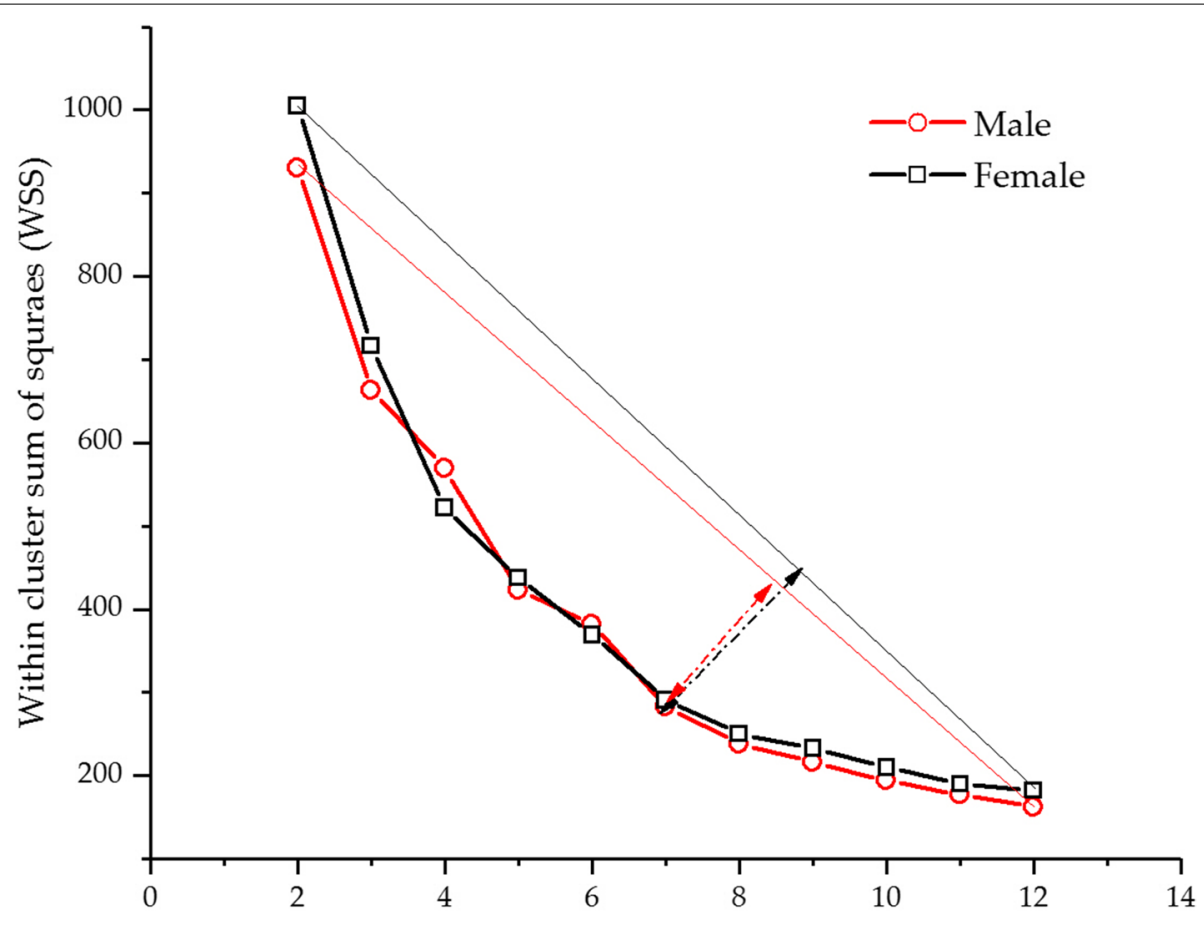

Number of clusters

Fig. 6 The relationship between the total within-cluster sum of squares (WSS) and cluster numbers

races, particularly Asians. Therefore, the design of knee prostheses for Thais should be improved to suitably accommodate the Thai knee.

The results revealed a mismatch between the Thai tibia and the commonly available tibial component. Figure 4 depicted the correlation between the tibial component and proximal tibia of Thais. The findings revealed a relative correlation with Sixma, Nexgen, and Scorpio but a low correlation with Genesis II, which may be caused by a low aspect ratio by design. This aspect ratio may be appropriate for Westerns and Caucasians. All prostheses systems were undersized in ML with the smaller AP size and overhung in ML with the larger AP size, a fact especially noticeable in the male group. Regardless of gender, the tibial aspect ratio had a consistent negative correlation with increasing AP dimension. Compared to the tibial component, the Nexgen showed a positive correlation in aspect ratio change, whereas the others showed a relatively constant ratio. The constant aspect ratio of the knee prosthesis did not correspond to the anatomy of the Thai tibia. The mismatches between implant dimensions and bone caused an overhang or underhang of the tibial component. The tibial overhanging may cause soft tissue irritation and knee pain, while the underhanging of the tibial component has the potential to increase tibial bone resorption, which is one of the causes of aseptic loosening $[3,12,26]$. As a result, Thai-specific knee prostheses are required.
K-means clustering analysis was used to find the optimum number of tibial component sizes. Figure 4 shows the correlation between the ML and AP of the proximal tibia. This correlation was used to find the number of tibial component sizes which covered Thai knees. The number of clusters ranged from two to twelve for clustering analysis. The cluster centroid and total within-cluster sum of squares (WSS) were calculated for each cluster. The correlation between WSS and cluster numbers was plotted as curves to find the optimal cluster numbers, as shown in Fig. 6.

A bending point location in the graph is usually used to estimate the number of appropriate clusters [36]. When the bending point was not clearly visible, the longest distance between a straight line connecting the first and last points of clusters and any point of cluster indicated the

Table 8 The recommended tibial component size for the Thais

\begin{tabular}{llllll}
\hline Size & \multicolumn{2}{l}{ Male } & & \multicolumn{2}{l}{ Female } \\
\cline { 2 - 3 } \cline { 5 - 6 } & AP $(\mathbf{m m})$ & ML $(\mathbf{m m})$ & & AP $(\mathbf{m m})$ & ML $(\mathbf{m m})$ \\
\hline 1 & 42 & 72 & 38 & 62 \\
2 & 44 & 75 & 40 & 65 \\
3 & 46 & 72 & 42 & 62 \\
4 & 46 & 78 & 43 & 68 \\
5 & 48 & 75 & 44 & 68 \\
6 & 50 & 78 & 46 & 71 \\
7 & 52 & 80 & 48 & 65
\end{tabular}




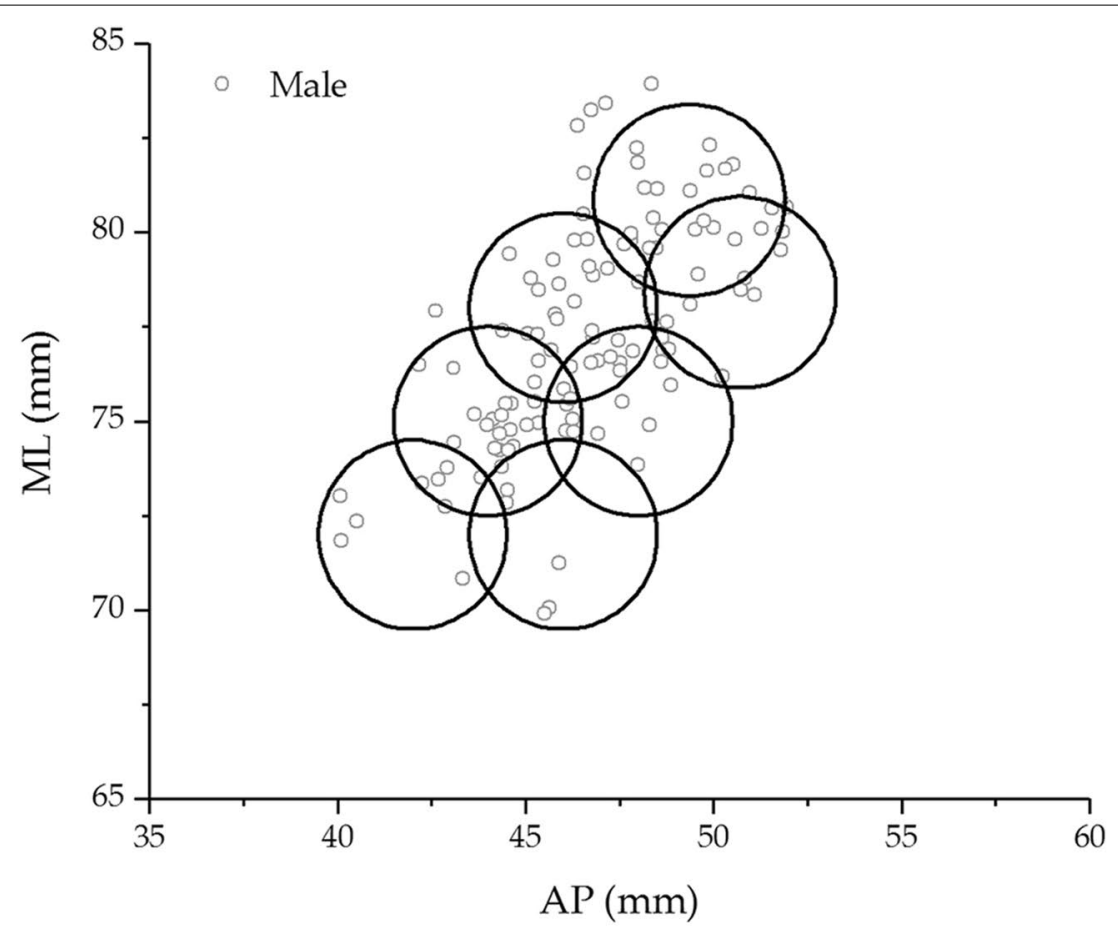

(a)

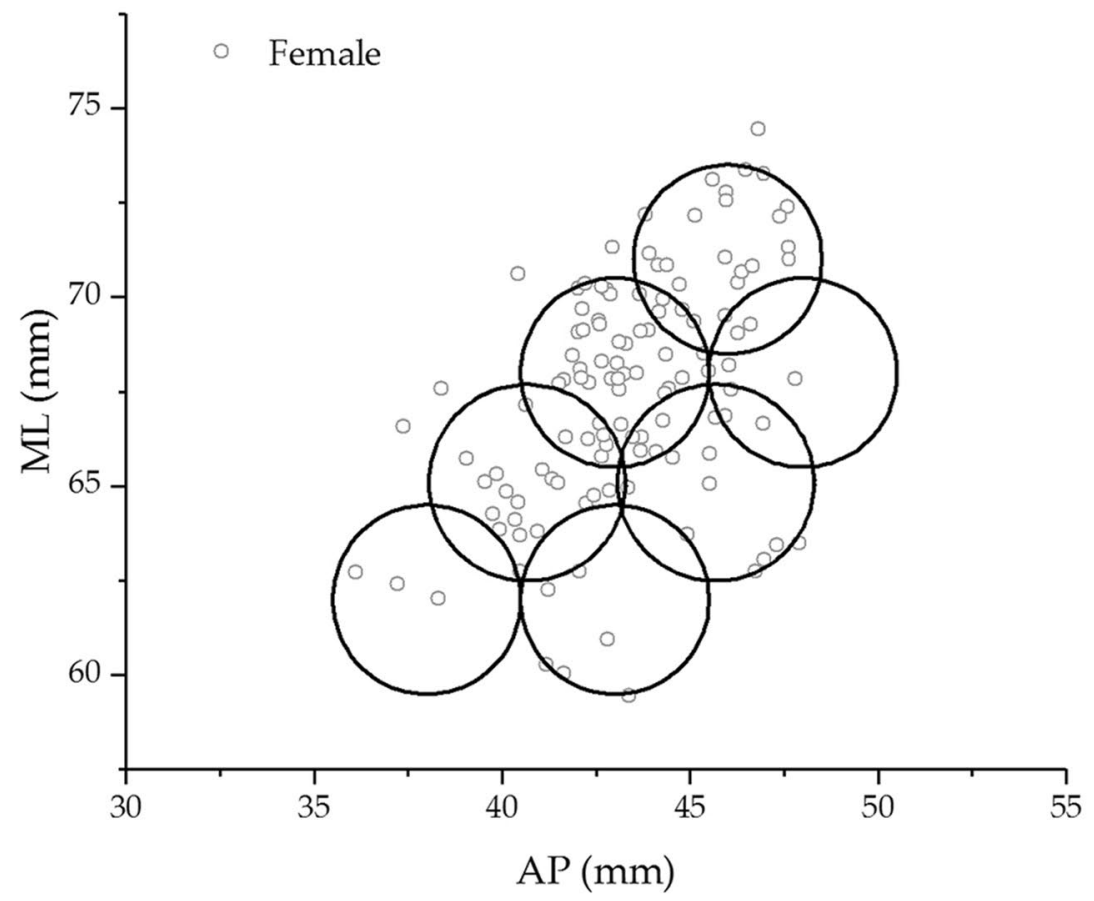

(b)

Fig. 7 The percentages of the tibial component coverage on tibial cut surface related to AP and ML dimensions. a males and $\mathbf{b}$ females 
optimal number of clusters. In Fig. 6, the result revealed seven sizes of the tibial component, the optimum number for coverage of the Thai tibia. The centroid data for each group represented the ML and AP dimensions of the tibial component for Thais. Table 8 shows the number of sizes and dimensions of tibial components for Thais.

The newly designed tibial components (seven sizes) were plotted as a circle, with each size of AP and ML dimensions as the center of the circle. The circle's radius of $2.5 \mathrm{~mm}$ represented a range of criteria for underhang or overhang of the implant [7]. The absolute overhang was defined as more than $2 \mathrm{~mm}$, while the relative overhang was defined as less than $2 \mathrm{~mm}$. Absolute underhang was defined as under cover of more than $5 \mathrm{~mm}$, while relative underhang was determined under 2 to $5 \mathrm{~mm}$ [20]. Figure 7 depicted the coverage percentages between the tibial component and the tibial cut surface according to AP and ML dimensions. The findings revealed that females had coverage percentages of around $96 \%$, while males had coverage percentages of $95 \%$. However, the tibial components in this study were symmetrical designs. The medial plateau is more extensive than the lateral plateau; thus, the asymmetry design should also be considered.

In this study, there were some limitations. Firstly, the volunteers were healthy, not TKA candidates. The morphometric dimension of the normal knee may differ from that of the osteoarthritic knee [8]. Secondly, most volunteers lived in the Northeast of Thailand. The distinction in residence may affect the average values of proximal tibia morphology in Thais [34]. Thirdly, while this study used 3D models to measure morphometric parameters, the effect from cartilage thickness was not included. These models were reconstructed using CT images, depending on the threshold value and mesh quality. Finally, this study only measured one resected surface in the tibia, but the actual surgery determines the depth of the cut surface depending on the stage of disease [23]. Despite these limitations, the current study provides relevant and necessary morphometric data on Thai tibias.

\section{Conclusion}

The morphometric parameters of the Thai proximal tibia were not significantly different between the right and left sides. When comparing with gender, all male parameters were significantly higher than females. The majority of the pairwise parameters had a strong positive correlation. There was a significant difference in morphometric dimensions between nationalities, with Thais having smaller proximal tibias than Caucasians. There was also a mismatch between the Thai proximal tibia and the tibial component of TKA, which is generally used. The design of the tibial component should be recommended to cover the anatomy of the Thai knee, especially in the ML and AP sizes. This study provides essential information for the development of Thai-specific knee prostheses.

\section{Acknowledgments}

The authors would like to acknowledge Suranaree University of Technology, Suranaree imaging center, Suranaree University of Technology Hospital, and Institute of engineering.

\section{Informed consent}

Informed consent was obtained from all individual participants.

\section{Authors' contributions}

CP: acquisition of data of the study, analysis, and interpretation of data, figures preparation, drafting the article. SR: conception, design and supervision of the study, analysis, interpretation of data, and revising the manuscript critically for important intellectual content. BS: analysis and interpretation of data. The author(s) read and approved the final manuscript.

\section{Funding}

This research was funded by Health System Research Institute, grant number 60-020.

\section{Declarations}

\section{Ethics approval and consent to participate}

The study was conducted according to the guidelines of the Declaration of Helsinki and approved by the Institutional Review Board (or Ethics Committee) of Suranaree University (EC59-60, 29 December 2016).

\section{Competing interests}

The authors declare no conflict of interest.

\section{Author details}

${ }^{1}$ School of Mechanical Engineering, Suranaree University of Technology, Nakhon Ratchasima 30000, Thailand. ${ }^{2}$ School of Orthopedics, Suranaree University of Technology, Nakhon Ratchasima 30000, Thailand.

Received: 9 September 2021 Accepted: 10 November 2021

Published online: 20 December 2021

\section{References}

1. Bansal V, Mishra A, Verma T, Maini D, Karkhur Y, Maini L (2018) Anthropometric assessment of tibial resection surface morphology in total knee arthroplasty for tibial component design in Indian population. J Arthroscopy Joint Surg 5(1):24-28

2. Bloebaum R, Bachus K, Mitchell W, Hoffman G, Hofmann A (1994) Analysis of the bone surface area in resected tibia: implications in tibial component subsidence and fixation. Clin Orthop Relat Res 309:2-10

3. Bonnin MP, Schmidt A, Basiglini L, Bossard N, Dantony E (2013) Mediolateral oversizing influences pain, function, and flexion after TKA. Knee Surg Sports Traumatol Arthrosc 21(10):2314-2324

4. Canale ST (2003) Campbell's operative orthopaedics, 10th edn. Mosby Publishing, Philadelphia

5. Chaichankul C, Tanavalee A, Itiravivong P (2011) Anthropometric measurements of knee joints in Thai population: correlation to the sizing of current knee prostheses. Knee 18(1):5-10

6. Chantarapanich N, Rojanasthien S, Chernchujit B, Mahaisavariya B, Karunratanakul K, Chalermkarnnon P, Glunrawd C, Sitthiseripratip K (2017) 3D $\mathrm{CAD} /$ reverse engineering technique for assessment of Thai morphology: proximal femur and acetabulum. J Orthop Sci 22(4):703-709

7. Cheng C-K, Lung C-Y, Lee Y-M, Huang C-H (1999) A new approach of designing the tibial baseplate of total knee prostheses. Clin Biomech 14(2):112-117

8. Cheng FB, Ji XF, Lai Y, Feng JC, Zheng WX, Sun YF et al (2009) Threedimensional morphometry of the knee to design the total knee arthroplasty for Chinese population. Knee 16(5):341-347 
9. Dai Y, Bischoff JE (2013) Comprehensive assessment of tibial plateau morphology in total knee arthroplasty: influence of shape and size on anthropometric variability. J Orthop Res 31(10):1643-1652

10. Erkocak OF, Kucukdurmaz F, Sayar S, Erdil ME, Ceylan HH, Tuncay I (2016) Anthropometric measurement of tibial plateau and correlation with the current tibial implants. Knee Surg Sports Traumatol Arthrosc 24(9):2990-2997

11. Fuller CB, Farnsworth CL, Bomar JD, Jeffords ME, Murphy JS, Edmonds EW et al (2018) Femoral version: comparison among advanced imaging methods. J Orthop Res 36(5):1536-1542

12. Gu S, Kuriyama S, Nakamura S, Nishitani K, Ito H, Matsuda S (2019) Underhang of the tibial component increases tibial bone resorption after total knee arthroplasty. Knee Surg Sports Traumatol Arthrosc 27(4):1270-1279

13. Hafez MA, Sheikhedrees SM, Saweeres ES (2016) Anthropometry of Arabian arthritic knees: comparison to other ethnic groups and implant dimensions. J Arthroplast 31(5):1109-1116

14. Hitt K, Shurman JR 2nd, Greene K, McCarthy J, Moskal J, Hoeman T et al (2003) Anthropometric measurements of the human knee: correlation to the sizing of current knee arthroplasty systems. J Bone Joint Surg Am 85:115-122

15. Holland TD (1991) Sex assessment using the proximal tibia. Am J Phys Anthropol 85(2):221-227

16. Huang A-B, Luo X, Song C-H, Zhang J-Y, Yang Y-Q, Yu J-K (2015) Comprehensive assessment of patellar morphology using computed tomography-based three-dimensional computer models. Knee 22(6):475-480

17. Incavo SJ, Ronchetti PJ, Howe JG, Tranowski JP (1994) Tibial plateau coverage in total knee arthroplasty. Clin Orthop Relat Res 299:81-85

18. Insall JN, Dorr LD, Scott RD, Scott WN (1989) Rationale of the knee society clinical rating system. Clin Orthop Relat Res 248:13-14

19. Islam K, Dobbe A, Komeili A, Duke K, El-Rich M, Dhillon S, Adeeb S, Jomha NM (2014) Symmetry analysis of talus bone. Bone Joint Res 3(5):139-145

20. Jin C, Song EK, Prakash J, Kim SK, Chan CK, Seon JK (2017) How much does the anatomical Tibial component improve the bony coverage in Total knee arthroplasty? J Arthroplast 32(6):1829-1833

21. Karimi E, Zandi R, Norouzian M, Birjandinejad A (2019) Correlation of anthropometric measurements of proximal tibia in Iranian knees with size of current Tibial implants. Arch Bone Jt Surg 7(4):339-345

22. Koo TK, Li MY (2016) A guideline of selecting and reporting Intraclass correlation coefficients for reliability research. J Chiropr Med 15(2):155-163

23. Kwak DS, Surendran S, Pengatteeri YH, Park SE, Choi KN, Gopinathan P et al (2007) Morphometry of the proximal tibia to design the tibial component of total knee arthroplasty for the Korean population. Knee 14(4):295-300

24. Liu Z, Yuan G, Zhang W, Shen Y, Deng L (2013) Anthropometry of the proximal tibia of patients with knee arthritis in Shanghai. J Arthroplast 28(5):778-783

25. Ma QL, Lipman JD, Cheng CK, Wang XN, Zhang YY, You B (2017) A comparison between Chinese and Caucasian 3-dimensional bony morphometry in Presimulated and Postsimulated osteotomy for Total knee arthroplasty. J Arthroplast 32(9):2878-2886

26. Mahoney OM, Kinsey $T$ (2010) Overhang of the femoral component in total knee arthroplasty: risk factors and clinical consequences. J Bone Joint Surg Am 92(5):1115-1121

27. Marutho D, Handaka SH, Wijaya E, Muljono (2018) The determination of cluster number at k-mean using elbow method and purity evaluation on headline news. 2018 International Seminar on Application for Technology of Information and Communication

28. Matsuda S, Miura H, Nagamine R, Mawatari T, Tokunaga M, Nabeyama $R$ et al (2004) Anatomical analysis of the femoral condyle in normal and osteoarthritic knees. J Orthop Res 22(1):104-109

29. Meftah M, Ranawat AS, Ranawat CS (2012) Ten-year follow-up of a rotating-platform, posterior-stabilized total knee arthroplasty. J Bone Joint Surg Am 94(5):426-432

30. Mensch JS, Amstutz HC (1975) Knee morphology as a guide to knee replacement. Clin Orthop Relat Res 112:231-241

31. Miyatake N, Sugita T, Aizawa T, Sasaki A, Maeda I, Kamimura M et al (2016) Comparison of intraoperative anthropometric measurements of the proximal tibia and tibial component in total knee arthroplasty. J Orthop Sci 21(5):635-639
32. Phombut C, Rooppakhun S, Sindhupakorn B (2021) Morphometric analysis and three-dimensional computed tomography reconstruction of Thai distal femur. Appl Sci 11(3):1052

33. Reddy AVG, Sankineani SR, Agrawal R, Thayi C (2020) Comparative study of existing knee prosthesis with anthropometry of Indian patients and other races, a computer tomography 3D reconstruction-based study. J Clin Orthop Trauma 11:S228-SS33

34. Rooppakhun S, Surasith P, Vatanapatimakul N, Kaewprom Y, Sitthiseripratip K (2010) Craniometric study of Thai skull based on three-dimensional computed tomography (CT) data. J Med Assoc Thail 93(1):90-98

35. Stulberg BN, Dombrowski RM, Froimson M, Easley K (1995) Computed tomography analysis of proximal tibial coverage. Clin Orthop Relat Res 311:148-156

36. Tripathi S, Bhardwaj A, Eswaran P (2018) Approaches to clustering in customer segmentation. Int J Eng Technol 7:802

37. Uehara K, Kadoya Y, Kobayashi A, Ohashi H, Yamano Y (2002) Anthropometry of the proximal tibia to design a total knee prosthesis for the Japanese population. J Arthroplast 17(8):1028-1032

38. Westrich GH, Haas SB, Insall JN, Frachie A (1995) Resection specimen analysis of proximal tibial anatomy based on 100 total knee arthroplasty specimens. J Arthroplast 10(1):47-51

39. Yue B, Varadarajan KM, Ai S, Tang T, Rubash HE, Li G (2011) Differences of knee anthropometry between Chinese and white men and women. J Arthroplast 26(1):124-130

40. Zhang Z, Zhang Q, Zhao G, Huang J, Chen Z, Jin Z et al (2019) Morphological measurements of the Normal distal femur and proximal tibia between Han Chinese and Mongolian Chinese in a healthy Chinese population. Int J Morphol 37:664-670

\section{Publisher's Note}

Springer Nature remains neutral with regard to jurisdictional claims in published maps and institutional affiliations.

\section{Submit your manuscript to a SpringerOpen ${ }^{\circ}$ journal and benefit from:}

- Convenient online submission

- Rigorous peer review

- Open access: articles freely available online

- High visibility within the field

Retaining the copyright to your article

Submit your next manuscript at springeropen.com 